\title{
CULTURA POLÍTICA PARTICIPATIVA E DESCONSOLIDAÇÃO DEMOCRÁTICA reflexões sobre o Brasil contemporâneo
}

\author{
Marcello Baquero \\ Professor do Programa de Pós-Graduação em Ciência Política da Universidade Federal do Rio Grande do Sul
}

\begin{abstract}
Resumo: Exame de alguns dos fatores histórico-estruturais, cuja influência tem se mostrado significativa na estruturação de padrões de atitudes e comportamentos de desconfiança e desencanto da sociedade brasileira em relação às suas instituições políticas e, principalmente, aos políticos. Os resultados do estudo indicam que a existência de fatores dessa natureza acabam por descaracterizar a democracia no país e permitem o surgimento de formas antidemocráticas de governar.

Palavras-chave: cultura política; instituições políticas; democracia.
\end{abstract}

A s dificuldades que o Brasil enfrenta presentemente de solidificação de seus partidos políticos como mediadores entre Estado e sociedade; a não-consolidação de uma economia que estabeleça parâmetros mínimos de redistribuição de riqueza; e a onda generalizada de corrupção institucional e o agravamento da situação social no país, propiciam algumas reflexões sobre o impacto desses fatores na estruturação da cultura política do país, bem como uma avaliação do próprio processo de construção democrática. De maneira geral, nos últimos anos, as pesquisas de opinião pública têm revelado um declínio acentuado da confiança que os brasileiros depositam nas instituições políticas e particularmente na classe política. Nota-se claramente, também, uma fragilização dos laços sociais e a institucionalização do individualismo, com o interesse privado ou individual se sobrepondo ao interesse coletivo. Poder-se-ia argumentar que essa situação não constitui uma novidade, pois sempre foi assim, e, ainda mais, a presença desses fatores na sociedade brasileira não poderia ofuscar os avanços obtidos no campo da democratização ao longo das duas últimas décadas.

$\mathrm{O}$ argumento que este trabalho se propõe a desenvolver tem o objetivo de avaliar se, de fato, os avanços no campo formal da política têm sido suficientes para gerar uma base na qual esteja se desenvolvendo uma cultura política democrática e participativa. A problemática a ser discutida está centrada na idéia de que, na verdade, houve uma modificação nas atitudes e no comportamento dos brasileiros em relação à política, fruto de um conjunto de fatores (o mercado, a globalização, a informática, entre outros), porém, na essência, os brasileiros continuam a desacreditar nas instituições que constituem o pilar da democracia representativa. Observa-se uma adaptação das instituições democráticas a uma prática de uso de procedimentos antidemocráticos que pervertem a representação política, gerando dúvidas e incertezas sobre o futuro da democracia. Isso se verifica não no sentido de favorecer retrocessos institucionais ou rupturas profundas, mas na institucionalização de atitudes de indiferença, apatia e distanciamento da arena política, e na crença de que não há nada que se possa fazer para mudar o atual estado de coisas. Tais atitudes podem ser muito mais deletérias ao processo de construção democrática a longo prazo. Vêse, por exemplo, que apesar de vários mandatários latinoamericanos terem sido depostos por mobilizações populares (Collor no Brasil, Fujimori no Peru, Bucaram e Mahuad, no Equador, e Peres, na Venezuela), essas mobilizações não conseguiram se transformar em eixos permanentes de maior participação da sociedade civil. A nãoresolução dos problemas mais imediatos (nas áreas de emprego, saúde e educação), que levaram à deposição desses executivos, parece ter operado para gerar um sentimento de impotência, acirrado pela forma de funciona- 
mento das leis, dando a idéia de que a justiça se faz apenas para os mais abastados.

Para respaldar esta análise, busca-se, num primeiro momento, resgatar alguns fatores de caráter histórico-estrutural que possibilitem uma compreensão contextualizada de como foram condicionadas as crenças e os valores em relação à política. Não se trata de estabelecer um determinismo histórico, mas de tentar compreender a influência que essas matrizes tiveram na estruturação de uma mentalidade coletiva que privilegia o distanciamento, o desencanto e a desconfiança generalizada. Num segundo momento, avaliam-se, de maneira ampla, resultados de pesquisas de opinião, que mostram haver a institucionalização de uma cultura política fragmentada e de desconfiança. Finalmente, sugere-se, pela importância, o desenvolvimento de associações informais, as quais deveriam funcionar concomitantemente com as organizações tradicionais formais, com vistas a uma cidadania mais crítica e participativa e com mais capital social.

\section{RETROSPECTO HISTÓRICO}

Fica claro, hoje, que o Estado brasileiro, ao contrário das nações européias, nunca foi capaz de expressar sua própria história e que tem sido, antes de mais nada, um receptor aberto da história do Ocidente desenvolvido. Com efeito, a compreensão da especificidade histórica do país é condição indispensável para reconceituar o sentido da política e a natureza das relações sociais aí existentes.

Freqüentemente se constata, na bibliografia sobre a evolução do Estado no Brasil, e com certa razão, a influência de um passado de instabilidade política e econômica, bem como de um legado autoritário que tem obstaculizado a construção de uma cultura política verdadeiramente democrática no País.

Uma perspectiva teórica que dominou o pensamento político brasileiro por muito tempo dizia respeito ao impacto dos fatores étnico-culturais na formação da sociedade brasileira. Essa abordagem, denominada culturalista, trabalhando no plano simbólico-ideológico, examinou de que forma se institucionalizou o poder político no Brasil. Dessa perspectiva procurava encontrar as raízes do caráter nacional da nação.

Entre os autores mais significativos associados a esta linha de pensamento encontram-se Joaquim Nabuco, Alberto Torres, Oliveira Viana, Azevedo Amaral, Gilberto Freire, Guerreiro Ramos e Francisco Campos. O ponto de convergência entre eles está na tentativa de resgatar as matrizes estruturais da sociabilidade brasileira. $\mathrm{O}$ fator preponderante desta linha de análise é a influência do clientelismo, o personalismo e a incapacidade do povo na suposta incapacidade da sociedade em se mobilizar autonomamente para fiscalizar e modificar o processo político. A forma de evolução do Estado teria propiciado a socialização de valores de distanciamento e apatia tornando sua influência na política improvável. Essa tendência não participativa era conseqüência de governos e de uma estrutura social que favoreciam muito mais a desmobilização e a inércia do que a participação cidadã. Estabeleceu-se um consenso generalizado de que o país não tinha capacidade de reformar efetivamente as estruturas tradicionais do Estado, gerando um descompasso entre um acelerado desenvolvimento econômico e uma estagnação do desenvolvimento político, materializado na ausência de uma cidadania organizada e eficaz na defesa de seus interesses, o que somou uma deficiente mediação entre Estado-sociedade e partidos.

Tais elementos deram suporte ao surgimento da tecnocracia, que serviria de eixo catalisador do "desenvolvimento" do País a partir dos anos 50, colocando a participação popular como algo secundário.

A tecnocracia surge, portanto, como o principal ator da industrialização no Brasil. Assim, enquanto o núcleo das decisões estatais ficou a cargo dos técnicos insulados nas agências estatais, deixou-se o espólio do sistema para o uso da política de clientela e do corporativismo; práticas que seriam realizadas, aí sim, pela classe política situada no parlamento. Como o parlamento passa a desempenhar um papel historicamente secundário na esfera das grandes decisões estatais no Brasil, decorrente dessa dinâmica, a hipertrofia do poder Executivo passa a ser uma característica prevalecente no Brasil.

Uma das conseqüências desse tipo de pensamento culturalista, por exemplo, foi a sugestão de Oliveira Viana e de seus seguidores de que somente um sistema autoritário e centralizador poderia construir o verdadeiro Estado nacional.

Nesse sentido, o Estado, dominado pela tecnocracia e por procedimentos clientelísticos, personalistas e corporativistas, propicia a institucionalização do chamado Estado Patrimonialista (Uricoechea, 1978).

Quanto ao patrimonialismo, encontra-se na obra de Raymundo Faoro (1989) um dos principais trabalhos acerca desse tema. Para o autor, o atraso político brasileiro, do ponto de vista da incorporação da sociedade civil, tem a ver com a forma de estruturação da burocracia no país. Fruto do avanço sistemático do poder político no contro- 
le da economia e da diferenciação social, o patrimonialismo ou o mercantilismo estatal destruiu a institucionalização dos direitos individuais. Os burocratas da corte passaram a ter status maior do que os da fidalguia, que perdem seu poder econômico durante o processo de expansão comercial.

Esse conjunto de fatores da sociabilidade brasileira propiciou, segundo Buarque de Holanda (1992), o estabelecimento de quatro elementos que caracterizaram a organização social brasileira: ausência da tendência de autogoverno, a qual significava a ausência de solidariedade comunitária e de maneiras espontâneas de auto-organização política; virtudes inativas, ou seja, o ser social não reflete ativamente para transformar a realidade, mas procura uma razão externa a sua existência; e razão reflexiva, a qual provoca um pensamento que impede rompimentos, sustenta uma consciência conservadora e um domínio dos interesses pelas paixões.

De acordo com essa concepção, a sociabilidade brasileira nasceu influenciada pela pirâmide familiar, tendo como fundamento a organização patriarcal, a fragmentação social, as lutas entre as famílias, as virtudes inativas e a Ética da aventura. Originalmente o caudilhismo e, posteriormente, o coronelismo, que implicava a existência de lideranças carismáticas, substituíam a racionalidade dos interesses individuais e estabeleciam a matriz sobre a qual a organização social e as fundações da política e do Estado foram delineadas.

Com efeito, na medida em que as relações afetivas ou familiares precederam a constituição do espaço público, o poder público incorporou uma dimensão personalista em que o carisma-onipotente e a dependência do homem comum geraram uma atitude instrumental em relação à política.

Nos anos 80, a abordagem culturalista solidifica-se com a obra de Roberto DaMata (1993) em sua análise dos fenômenos sociais e da linguagem, examinando as causas da desigualdade e das formas de hierarquia existentes no Brasil. Já no exame das representações sociais e das concepções de cidadania, verifica-se o confronto da autoridade social, baseada, de um lado, no personalismo e na identidade vertical, e, de outro, na lei positiva. Nesse contexto, segundo DaMata, enquanto o conhecido medalhão determina as iniciativas da ação coletiva, o personalismo, como modelo típico desse tipo de relações sociais, institucionaliza-se.

A conclusão do autor é a de que a sociedade brasileira pode ser caracterizada como sendo híbrida, pois combina uma identidade horizontal, tipicamente ocidental e baseada no direito natural, com uma identidade vertical, característica das sociedades não-ocidentais, nas quais predominam as tradições e a continuidade cultural.

Perspectiva diferente, na dimensão institucional, apresenta Raymundo Faoro na obra Os donos do poder (1989), em que caracterizava o Estado no Brasil como uma extensão do patrimonialismo ibérico, um poder imposto a uma sociedade dominada pela política de manutenção do poder vigente.

Nesse sentido, pode-se dizer que a experiência política brasileira tem se caracterizado pela predominância de formas autoritárias de governo, gerando, como conseqüência, uma restrição às possibilidades de uma participação política mais efetiva. O impacto do autoritarismo, ao longo das últimas décadas, não permitiu que se desenvolvesse um cenário no qual a ingerência da sociedade civil no Estado fosse significativa. Após 1974, com o processo de abertura política, o país atravessaria fases com amplas manifestações de massa, dentre elas a marcha pelas diretas, em 1984; as manifestações pelo impeachment do presidente Collor; a CPI dos anões, e as várias CPIs que têm se instalado ao longo do tempo. Esses acontecimentos, entretanto, que em outras circunstâncias poderiam constituir matrizes capazes de catalisar modalidades de participação mais duradouras e objetivas, acabam sendo relegados a um segundo plano em relação às crises econômica e social que vêm abalando o país, apesar da existência de indicadores estatísticos que mostram uma expansão industrial e uma recuperação da economia.

Outrossim, historicamente, os instrumentos necessários para uma construção democrática caracterizada pela participação política estavam ausentes ou funcionavam de maneira precária ou com predisposições ideológicas determinadas. Um dos instrumentos de grande impacto, nesse sentido, são os meios de comunicação. Ao lado disso, o(s) sistema(s) partidário(s) frágil(eis) e com pouca credibilidade não têm constituído um instrumento de canalização, de mobilização e de participação política. Nesse contexto, os pleitos eleitorais têm se caracterizado, ao longo do tempo, por apelos subjetivos, emocionais, personalistas e clientelistas.

Diante desse cenário, caberia indagar que tipo de construção democrática está em andamento no Brasil?

\section{DEMOCRACIA E CULTURA POLÍTICA}

Um conceito que surgiu nos últimos anos, para avaliar a saúde democrática do país, é a desconsolidação demo- 
crática. Típico desse processo seria o uso privado das instituições públicas, que a versão da democracia contemporânea tem possibilitado, em que os poderes e os interesses econômicos utilizam os poderes políticos e as instituições democráticas para continuar a exercer, com legitimidade e eficácia, sua dominação e seu regime de enriquecimento.

Para grande parcela da comunidade acadêmica, parece que a versão duracionista da democracia é mais importante do que os resultados sociais que ela gera. Pensa-se que uma democracia se consolida meramente pela sua capacidade de sobreviver a atentados contra sua institucionalidade. O que constatamos no Brasil contemporâneo é que a democracia está se sustentando, mas suas instituições, longe de se consolidarem, estão cada vez mais submetidas aos interesses privados dos setores econômicos. Schmitter (1994), em uma avaliação das democracias latino-americanas, porém aplicável ao caso brasileiro, sugere que, apesar das instituições funcionarem antidemocraticamente com governos que não governam, parlamentos com mais representatividade privada do que política, eleições que elegem candidatos mas não os legitimam, instituições políticas que servem para o linchamento político e vinganças privadas, dão lugar a uma desordem democrática capaz de desordenar qualquer ordem e ordenamento social, mas que, paradoxalmente, são naturalizadas por toda a sociedade. Conseqüência dessa desordem é a idéia de que uma alternativa aos déficits de representação política seria a maior participação política e, ignora-se, no entanto, que a participação requer uma melhoria da própria representação, o que em realidade não ocorre.

Em conseqüência disso, tem-se tornado corriqueiro examinar as conseqüências dos déficits de representação política, deixando-se de examinar suas causas reais; de maneira geral, o Congresso e os partidos políticos aparecem como os principais responsáveis pelas falhas na representação política. Sem eximir sua parte nesse processo, seria pertinente resgatar a influência dos condicionantes histórico-sociais no processo de representação política e de sua crise. Esse problema se agrava na atualidade em virtude do aprofundamento da heterogeneidade estrutural, que torna quase inviável a representação efetiva dos diferentes interesses sociais.

O papel dos partidos políticos se vê hoje comprometido na sua função de agregação de interesses, pela insuficiência da consolidação democrática. Por um lado, o modelo político vigente tem permitido maior concentração de renda, legitimada pelo dogma neoliberal; por outro, constata-se, simultaneamente, um crescimento da exclusão social e o aumento da pobreza, transformando a sociedade brasileira não numa sociedade de interesses, mas numa nação de necessidades. Entretanto, diferentemente dos interesses que podem ser objetivamente representados, as necessidades passam pelo crivo imaginário dos representantes eleitos e, portanto, de um modo geral, não são representadas politicamente.

Nos últimos anos, assistimos a uma reconversão da representação política que tem se orientado na defesa dos interesses privados. Dessa forma, ao mesmo tempo que se legitima democraticamente uma dominação mais eficaz sobre a sociedade e uma maior concentração de riquezas, as instituições políticas democráticas são deslegitimadas.

A conseqüência da grave crise de representação política que o país vive tem redundado numa situação paradoxal em que, por um lado, busca-se o fortalecimento das instituições via reformas políticas, enquanto, por outro, buscam-se ou resgatam-se lideranças políticas cujo carisma é sempre proporcional à sua capacidade de se impor às instituições, o que acaba deslegitimando-as ainda mais. O resultado é a vigência de um ciclo vicioso, pois quanto maior a deslegitimação institucional, maior também a exigência de líderes carismáticos, os quais contribuem para neutralizar e desacreditar essas mesmas instituições.

A chamada durabilidade da democracia nesse contexto se dá às custas da perversão da legitimidade e da eficácia democráticas. Se a deslegitimação é grande, a ineficácia é maior, tendo em vista que os problemas do país cada vez mais são resolvidos por meios não democráticos (medidas provisórias; loteamento de cargos; negociações espúrias). Atualmente, por exemplo, fala-se muito na existência de um clientelismo de coalisão no governo federal (Avritzer, 2001).

$\mathrm{O}$ enriquecimento de uma pequena parcela da população brasileira, enquanto a maioria enfrenta as incertezas de uma economia de mercado e o não-atendimento de suas necessidades básicas, tem se tornado possível num contexto democrático, precisamente porque as instituições democráticas, em vez de desempenharem seus papéis específicos, de funcionarem democraticamente, têm, ao contrário, servido de apoio a setores que, com maior eficácia e legitimidade, reproduzem sua dominação e seu enriquecimento.

O neoliberalismo consegue, portanto, algo inédito, qual seja, sem destruir as instituições democráticas, submetêlas aos seus interesses e utilizá-las como instrumentos de 
dominação e enriquecimento ilícito. Nesse sentido, a democracia, na sua versão brasileira, tanto opera na gestão e administração de conflitos políticos, como permite a maior concentração de renda já observada na história do país. O paradoxo da democracia brasileira parece ser o de que, quanto mais ela dura, mais é pervertida, graças ao processo de globalização que tem possibilitado aos órgãos internacionais repetirem reiteradamente que sem legitimidade democrática não há apoio para o desenvolvimento, colocando o país numa situação de dependência neocolonialista (Casanova, 1995).

Talvez a institucionalização dos procedimentos, como sendo suficientes na construção democrática do país, tenha levado a negligenciar o fato de a democracia brasileira estar em processo de deterioração e degradação. A durabilidade do modelo democrático parece se sobrepor aos custos sociais de sua precariedade, visto serem eles internalizados e pagos com o aumento da pobreza e da exclusão social, ao passo que os lucros são externalizados, beneficiando os defensores da globalização. Por efeito dessas características, que operam contra as instituições democráticas, a democracia funciona cada vez mais antidemocraticamente e antiinstitucionalmente. Não é novidade, portanto, encontrar nas pesquisas de opinião pública o pouco apego e confiabilidade que os cidadãos brasileiros depositam nas suas instituições políticas. Em média, nos últimos 15 anos, os partidos são avaliados negativamente por mais de $60 \%$ da população brasileira (Baquero, 2000). O resultado é o distanciamento e a crise permanente das instituições políticas, levando ao fortalecimento do personalismo como instrumento de governabilidade. Na verdade, vivemos numa democracia permanentemente instável.

Assim, repensar o processo histórico que deu origem à formação de valores, normas e atitudes que norteiam o comportamento político na sociedade brasileira é, sem dúvida, uma tarefa bastante complexa, porque se de um lado nos deparamos com uma ampla bibliografia enfocando aspectos socioculturais, políticos e econômicos, de outro encontramos poucos estudos que nos permitam entender como se forjou a consciência política desta sociedade e de que modo ela tem se expressado em sua cultura política.

Se cultura política é vista ao mesmo tempo como causa e conseqüência do funcionamento do sistema político (Lamounier e Souza, 1991:311), pode-se afirmar que a cultura política de uma sociedade é resultado de um padrão de orientações cognitivas, emocionais e valorativas que, além de estáveis, tornam-se vivas e atuantes ao longo do tempo, pois "a menos que grandes rupturas históricas forcem os grupos sociais a redefinir esses padrões, a cultura política continuará a reproduzir-se de acordo com as matrizes originais".

Nesse sentido, o que importa destacar é que a cultura política ocupa um lugar central no cotidiano dos indivíduos, podendo servir tanto para regular a transmissão de valores políticos, quanto para legitimar o funcionamento das instituições políticas. A forma como se constrói e se difunde essa cultura está diretamente relacionada a como se reproduzem os comportamentos, as normas e os valores políticos de determinada comunidade.

Desse ponto de vista, a análise da cultura política de uma sociedade pressupõe a necessidade de caracterizar os diferentes contextos histórico-culturais que irão contribuir para a sua configuração. Assim sendo, a compreensão da sociedade brasileira deve ser vista como resultado de um processo interativo e cumulativo de experiências vividas, cujas matrizes políticas podem ser identificadas pela determinação de seu processo de formação histórica.

Dessa perspectiva, interessa destacar neste trabalho o impacto do modelo político vigente no país nas relações sociais e políticas. Até que ponto, por exemplo, o neoliberalismo não tem conseguido eliminar traços tradicionais da política brasileira. Em primeiro lugar, é importante constatar que a bibliografia sobre democracia, de modo geral, aponta para a necessidade de instituições mediadoras eficazes, democráticas e com legitimidade, como fator fundamental para o desenvolvimento democrático. Numa retrospectiva histórica daqueles países considerados avançados, verifica-se que conseguiram estabelecer uma democracia duradoura, atravessando etapas históricas que se iniciaram com relações primárias - a família era o núcleo em torno do qual os cidadãos transitavam. A identidade social era grupal ou familiar.

Com o advento da urbanização e da modernização, que impactaram a noção de família, surgem as chamadas relações sociais secundárias em que as instituições políticas, especificamente os partidos políticos, catalisam identidades coletivas. É a fase da consolidação da democracia representativa, na qual os partidos são os mediadores das demandas da sociedade civil. É a solidificação das relações secundárias que fortalecem o sistema democrático. No entanto, observa-se no Brasil o surgimento e prevalência das relações sociais terciárias, em virtude da precariedade dos partidos políticos. Por relações sociais terciárias entendese o estabelecimento de uma relação direta entre Estado e indivíduo, em detrimento dos partidos políticos. 
Relações sociais dessa natureza têm-se fortalecido nos últimos governos neoliberais, cuja estratégia, no campo político, orienta-se para fragilizar o sistema de representação política. Um dos exemplos disso seria o enfraquecimento da estrutura sindical. A própria instalação de uma economia de mercado, ao catalisar o desemprego estrutural e o surgimento de uma economia informal, vulnerabiliza os setores mais frágeis da sociedade. Os partidos, por sua vez, historicamente frágeis, tornam-se mais deficientes como instituições de identidades coletivas em economias de mercado.

Não é surpreendente, portanto, o surgimento do chamado neopopulismo, definido como surgimento de líderes personalistas que contam com o apoio da população em virtude de suas características pessoais e defendem o receituário neoliberal, o qual age contra essa mesma população para instalar a austeridade econômica e os ajustes estruturais que agravam a situação social do povo. $\mathrm{O}$ Brasil, junto com outros países da América Latina, como Peru e Argentina, é o exemplo mais emblemático desse neopopulismo contemporâneo.

Ao mesmo tempo, um componente que tem se tornado evidente no Brasil é a aceitação, por parte significativa da sociedade, de um discurso que contrapõe a continuidade ao caos, para viabilizar a manutenção no poder e a reeleição de líderes que defendem esse modelo. A vulnerabilidade objetiva da população, nesse contexto, possibilita que as pessoas internalizem a crença de que, a menos que se dê continuidade aos governos para terminar as reformas, o caos se instalará comprometendo a estabilidade democrática.

Aqui surge um outro ponto da cultura política brasileira a ser considerado. Estabeleceu-se uma relação causal entre estabilidade econômica e estabilidade social e democrática, desmentida pela realidade. A maior parte dos países do mundo em desenvolvimento, onde se alcançou a estabilidade econômica, está longe de ser modelo de estabilidade social, se por estabilidade social se entende a crença dos cidadãos na democracia e nas instituições em virtude de elas serem capazes de solucionar os problemas sociais básicos (transporte, educação, emprego e saúde). O que as pesquisas de opinião pública, feitas nos últimos anos no país, mostram é que há um declínio significativo de apoio dos cidadãos ao atual sistema político.

Uma das conseqüências mais marcantes do neoliberalismo também tem sido o de possibilitar o surgimento de organizações paraestatais, organizações que funcionam à margem da lei e que contam com o apoio significativo das populações mais carentes. Destaca-se aqui, especificamente, o narcotráfico. Essas organizações estão propiciando o aumento da criminalidade e da marginalização, levando os grupos tradicionalmente excluídos dos benefícios sociais a legitimar ações deletérias em nome de uma nova cidadania. Pesquisas realizadas na área antropológica mostram adolescentes que matam por um par de tênis porque consideram ser esse um ato de manifestação de cidadania.

Esses dados indicam que o país vive, no presente, uma situação em que prevalece o princípio de exclusão social. Paradoxalmente, os governantes tendem a considerar essa situação como inevitável e a desigualdade social, um fato natural.

Dessa maneira, constata-se uma crise dominante da legitimidade do Estado no país. As pessoas parecem não mais acreditar na autoridade constituída. Roberto DaMata (1993) ilustra bem esse ponto ao observar que as pessoas, quando se sentem ameaçadas, aumentam a altura das grades das suas residências, em vez de pressionar o Estado na busca de soluções para o problema da violência. $\mathrm{Na}$ área da educação pública, que conta com recursos materiais, quando insatisfeitos com a qualidade do ensino, não lutam por melhores escolas mas transferem seus filhos para escolas particulares.

Todos esses elementos sugerem que, longe de se estar construindo uma cultura política participativa e democrática, materializa-se uma cultura política fragmentada e individualista, com pouco capital social. Trata-se, portanto, de considerar importante que hoje o desenvolvimento de redes baseadas na confiança interpessoal poderia constituir o mecanismo de resgate da sociedade civil, para um comportamento mais crítico e fiscalizador da coisa pública. O que se observa, entretanto, é um sentimento generalizado de desconfiança entre as pessoas e em relação ao Estado e suas instituições.

Como decorrência dessa cultura, constata-se o surgimento de um eleitor individualista e pragmático, cujo comportamento político se guia por princípios de eficácia administrativa e capacidade gerencial e não por princípios ideológicos.

\section{CONCLUSÃO}

Examinou-se o processo de formação de crenças e atitudes da sociedade brasileira no momento atual, a partir de reflexões de caráter histórico, tendo como parâmetro os diferentes momentos em que foram estabelecidas as bases de 
um comportamento mais orientado a relações sociais de caráter paternalista, personalista e clientelista. Não surpreende, por exemplo, a pouca participação dos brasileiros na política num sentido mais amplo, que vá além do simples ato de votar. Vivemos presentemente uma situação de elevados déficits de capital social, que permite a permanência de uma cultura política desafeta à participação.

A maneira como a democracia funciona hoje possibilita a institucionalização de formas antidemocráticas de governar. $\mathrm{O}$ questionamento crescente de parte da sociedade civil às ações governamentais está ocasionando uma situação de erosão dos princípios democráticos, sem que isto signifique uma potencial ruptura institucional. O modelo neoliberal vigente parece ter conseguido estabelecer padrões de comportamento em que os cidadãos e as autoridades públicas se tornam indiferentes à continuidade de um conjunto de procedimentos que, claramente, compromete-se a construção democrática efetiva no país. Um dos pontos a enfatizar é o acúmulo de experiências que ocorre no país e, como forma antidemocrática de resolução de problemas, uma vez internalizados pelas pessoas, constitui a base de uma memória coletiva difícil de ser alterada. Nessa dimensão, a ausência de capital social, fruto da falta de confiança interpessoal e da falta de confiança nas instituições, pode levar à manutenção de um sistema democrático permanentemente instável.

\section{NOTA}

E-mail do autor: baquero@orion.ufrgs.br

\section{REFERÊNCIAS BIBLIOGRÁFICAS}

AVRITZER, L. "O pano de fundo da crise é a concepção de aliança política de FHC". Conjuntura Política. Minas Gerais, jun. 2001, p.1-4.

BAQUERO, M. A vulnerabilidade dos partidos politicos e a crise da democracia na América Latina. Porto Alegre, Editora da UFRGS, 2000 .

CASANOVA, P.G. O colonialismo global e a democracia. Rio de Janeiro, Civilização Brasileira, 1995.

DaMATA, R. "Reflexões sobre o público e o privado no Brasil: um ponto de vista perverso". Cadernos de Ciências Sociais. Minas Gerais, v.3, n.3, abr. 1993, p.51-62.

FAORO, R. Os donos do poder. Rio de Janeiro, Globo, 1989.

HOLANDA, S.B. de. Visão do paraíso. Rio de Janeiro, Brasiliense, 1992.

LAMOUNIER, B. e SOUZA, A. de. "Democracia e reforma institucional no Brasil: uma cultura política em mudança". Dados, v.34, n.3, 1991, p.311-348.

SCHMITTER, P. "Dangers and dilemmas of democracy". Journal of Democracy, v.5, n.2, 1994.

URICOECHEA, F. O minotauro imperial. São Paulo, Difel, 1978.

VIANA, O. Problemas de organização e problemas de decisão: o povo e o governo. Rio de Janeiro, Record Cultural, 1974 (Edição póstuma). 